\title{
Parent perspectives on school food allergy policy
}

S. Shahzad Mustafa ${ }^{1,2}$, Anne F. Russell ${ }^{3}$, Olga Kagan ${ }^{4}$, Lauren M. Kao ${ }^{5}$, Diane V. Houdek ${ }^{5}$, Bridget M. Smith ${ }^{5,6}$, Julie Wang ${ }^{7}$ and Ruchi S. Gupta ${ }^{5,8,9^{*}}$ (D)

\begin{abstract}
Background: Food allergy affects up to $8 \%$ of children in the U.S. There is minimal research to date on food allergy policies that are currently in place in schools and the opinions of parents of children with food allergy on the effectiveness of or need for these policies.

Methods: An electronic survey was disseminated to parents of children with food allergy. Frequencies were calculated to describe respondent characteristics and responses. Chi-square tests were performed to examine associations between school and child characteristics and outcomes.

Results: Of the 289 parent respondents, 27.4\% were unsure or felt school was unsafe for their child with food allergy. While the majority felt that the polices in their child's school were helpful, most also believed that implementation of additional polices was necessary, including availability of stock epinephrine (94.2\%), lunch menus with allergen information (86\%), ingredient labels on food items (81\%), and direct food allergy education for students (86\%). There were significant differences in school food allergy policy depending on the age of the student body, private versus public school, and geographic location.

Conclusions: While most schools reportedly have one or more food allergy policies in place, many parents have concerns over the safety of their child at school and feel that additional policies are necessary to improve the safety of the school environment for children with food allergy. The availability of stock epinephrine, improved allergen labeling of food and menus and increased food allergy education may be key policy areas on which to focus.
\end{abstract}

Keywords: Anaphylaxis, Food allergy, School, Policy, Epinephrine, Food labeling

\section{Background}

Schools must practice effective anaphylaxis prevention and preparedness strategies as increasing prevalence rates of childhood food allergy have created a significant public health issue. It is estimated that nearly 6 million U.S. children, or $8 \%$, now have some form of IgEmediated food allergy, with $30 \%$ of food allergic children reporting multiple food allergies [1,2]. Despite ongoing research into potential therapeutic options, current management is based on strict avoidance of known food allergens and appropriate response to accidental exposures [3]. Although fatalities from food allergic reactions in school are rare, food is often ubiquitous

\footnotetext{
*Correspondence: r-gupta@northwestern.edu

${ }^{5}$ Northwestern University Feinberg School of Medicine, Chicago, IL, USA

${ }^{8}$ Ann \& Robert H. Lurie Children's Hospital of Chicago, Chicago, IL, USA

Full list of author information is available at the end of the article
}

throughout the school setting, thus creating risks for accidental exposures in schools that may have varying levels of anaphylaxis preparedness. Since most children spend up to half their waking hours at school, management of food allergy in the school setting is an important issue.

The U.S. Department of Education has not established policy recommendations related to food allergy. While voluntary guidelines for the management of food allergy in schools have been developed by the Center for Disease Control, there remains significant heterogeneity in school preparedness for food allergic reactions and there is no consensus on which preventative policies work best for improving food allergy safety in schools $[4,5]$. The vast majority of schools have at least one student with food allergy, and one survey showed that $67 \%$ of schools had made at least one accommodation for children with

(c) The Author(s). 2018 Open Access This article is distributed under the terms of the Creative Commons Attribution 4.0 International License (http://creativecommons.org/licenses/by/4.0/), which permits unrestricted use, distribution, and 
food allergy (peanut-free tables, peanut ban in classrooms, or alternative meals) [6]. However, approximately $18 \%$ of children with food allergies have experienced an allergic reaction while at school and over 10\% of 5683 schools reported at least one anaphylactic event during the 20132014 academic year [6-9]. Therefore, parents and students may have significant concerns regarding the potential for food-induced allergic reactions at school as well as the ability of school staff to effectively manage anaphylaxis.

To date, little research has been conducted examining current food allergy policies in US school systems and even less on the opinions of parents of children with food allergy regarding those policies and their utility. Therefore, the goal of this study was to survey parents of children with food allergy to determine the food allergy policies that they are aware of in their child's school and their opinion on the effectiveness of or need for these policies. With a better understanding of school policies, stronger recommendations for food allergy management in schools may be made to promote a safe and conducive learning environment for all children.

\section{Methods}

An initial survey was developed with the goal of understanding school policies related to food allergy. The research domains were selected based on a review of relevant literature and included family demographics (age, gender, race, grade, allergic reaction experience, etc.), awareness of current school food allergy policies; acceptability, effectiveness, and feasibility of current policies; and desired school food allergy policies. Following initial survey development, cognitive interviews were conducted with a subset of parents $(n=5)$ recruited through food allergy support groups in order to refine the survey questions. The final survey tool consisted of 105 multiple-part, multiple-choice, and open-ended response questions with skip logic, which required approximately $10 \mathrm{~min}$ to complete. It is available upon request. Parents were asked to respond for only one of their children with food allergy. Severe allergic reaction was not defined for respondents. Respondents who reported that a given policy was in place at their child's school were asked if the policy was helpful, while those who reported that a given policy was not in place or were unsure were asked if they felt that the policy was needed. No incentive was offered for participation in the study. REDCap (Research Electronic Data Capture, Vanderbilt University) hosted at Northwestern University was used to administer the online survey [10].

\section{Selection of subjects}

Parents were recruited for participation through the Allergy and Asthma Network (AAN) and Mothers of
Children Having Allergies (MOCHA) listservs. The target population included parents of children with food allergies in grades 1-12. Eligible participants were invited to participate via an email containing a link to complete the survey. Consent was obtained before any participant could access the survey. The process of obtaining informed consent followed all applicable requirements. The survey was conducted from August 2016 through January 2017. No identifying information was collected and all responses were kept confidential on secure servers at Northwestern University. The study was deemed exempt by Northwestern University's Institutional Review Board.

\section{Statistical analyses}

All statistical analyses were performed in Stata 14.0 statistical software (Stata Corp, College Station, TX). Frequencies were calculated to describe respondent characteristics and responses. Responses to the policy questions were dichotomized into two categories: yes and no/unsure. Missing responses were coded with "no/ unsure." For demographic variables, missing variables were coded as "other" or were included in a separate category. To examine associations between school and respondent characteristics and outcomes, chi-square tests were performed.

\section{Results}

\section{Survey respondents}

Of 290 completed surveys, one was eliminated due to the child not meeting grade level eligibility criteria, resulting in a final sample of 289 responses included in the final analyses. The majority of respondents were mothers (91.3\%), had a household income of more than $\$ 100,000$ (55.4\%), and held a college degree or higher (85.5\%) (Table 1). Most respondents lived in the Northeast (35.3\%) or Midwest (36.3\%). The majority of children were male (63.4\%) and Caucasian (77.9\%). $70 \%$ of the children were in elementary grades (grades $1-5)$, and most attended a public school (78.6\%). The most common food allergens were peanut $(76.1 \%)$ and tree nuts $(77.2 \%)$ and the most common comorbid conditions were allergic rhinitis (78.9\%), asthma (55. $7 \%$ ), and atopic dermatitis (49.8\%). While $81 \%$ of respondents reported that their child had experienced at least one severe reaction in their lifetime, $82 \%$ reported that their child had never experienced a severe reaction in the school setting.

\section{Food allergy and anaphylaxis policies}

Of the 289 parent respondents, $18.7 \%$ felt that school was unsafe for their food allergic child, and an additional 8.7\% were unsure about their child's safety while at school (Table 2). Regarding the availability of epinephrine, 
Table 1 Respondent Demographics

\begin{tabular}{ll}
\hline Characteristic & Frequency, N (\%) \\
\hline Total Number of Respondents & 289 \\
Child's gender & $176(63.4)$ \\
Male & $99(34.3)$ \\
Female & $14(4.8)$ \\
Other/Would not like to report/Missing & \\
(missing = 12) & \\
Child's grade & $182(70.0)$ \\
Elementary (1-5) & $46(15.9)$ \\
Middle (6-8) & $35(12.1)$ \\
High school (9-12) & $26(9.0)$ \\
Missing & \\
Type of school & $227(78.6)$ \\
Public & $16(5.5)$ \\
Private & $29(10.0)$ \\
Religious School & $17(5.9)$ \\
Other & $146(50.5)$ \\
How many severe reactions has your child had in his or her lifetime \\
0 & $55(19.0)$ \\
1 & $88(30.5)$ \\
$>1$ & 17 .
\end{tabular}

How many severe reactions has your child had in school in his or her lifetime

0

$237(82.0)$

1

$35(12.1)$

$>1$

$17(5.9)$

How many severe reactions has your child experienced in school in the past year

$\begin{array}{ll}0 & 265(91.7) \\ 1 & 19(6.6) \\ >1 & 5(1.7) \\ \text { To which foods is your child allergic } & \\ \text { Peanut } & 220(76.1) \\ \text { Tree nut } & 223(77.2) \\ \text { Fin fish } & 21(7.3) \\ \text { Shellfish } & 41(14.2) \\ \text { Milk } & 106(36.7) \\ \text { Egg } & 97(33.56 \\ \text { Soy } & 27(9.3) \\ \text { Wheat } & 26(9.0) \\ \text { Sesame } & 55(19.0) \\ \text { Other } & 69(23.9)\end{array}$

Ethnicity (Hispanic or Latino)

Yes

No

Unknown

$12(4.2)$

$254(87.9)$

$20(6.9)$

Unspecified
Table 1 Respondent Demographics (Continued)

\begin{tabular}{|c|c|}
\hline Characteristic & Frequency, N (\%) \\
\hline \multicolumn{2}{|l|}{ Race } \\
\hline Black/African American & $9(3.1)$ \\
\hline White & $225(77.9)$ \\
\hline Asian & $11(3.8)$ \\
\hline American Indian/Alaska Native & $3(1.0))$ \\
\hline Native Hawaiian or other Pacific Islander & 0 \\
\hline Other & $16(5.5)$ \\
\hline Unknown & $25(8.7)$ \\
\hline \multicolumn{2}{|l|}{ Child's comorbid conditions } \\
\hline Asthma & $161(55.7)$ \\
\hline Eczema & $144(49.8)$ \\
\hline Seasonal allergy & $228(78.9)$ \\
\hline Indoor allergy & $98(33.9)$ \\
\hline Pet allergy & $153(52.9)$ \\
\hline Insect allergy & $25(8.7)$ \\
\hline Medication allergy & $61(21.0)$ \\
\hline None & $15(5.2)$ \\
\hline Other & $9(3.1)$ \\
\hline \multicolumn{2}{|l|}{ Respondent's relationship to child } \\
\hline Mother & $263(91.3)$ \\
\hline Father & $9(3.3)$ \\
\hline Grandparent & 0 \\
\hline Other & $3(1.0)$ \\
\hline Unknown & $14(4.8)$ \\
\hline \multicolumn{2}{|l|}{ Highest level of education } \\
\hline Some secondary school (9th grade and above) & $2(0.7)$ \\
\hline High school graduate or GED & $3(1.0)$ \\
\hline Some college & $20(6.9)$ \\
\hline College degree & 144 49.8) \\
\hline Master's degree & $80(27.7)$ \\
\hline Doctoral degree & $23(8.0)$ \\
\hline Unknown & $17(5.9)$ \\
\hline \multicolumn{2}{|l|}{ Income } \\
\hline$<\$ 50,000$ & $18(6.2)$ \\
\hline$\$ 50,000-\$ 74,999$ & $24(8.3)$ \\
\hline$\$ 75,000-\$ 99,999$ & 39 (13.5) \\
\hline$\$ 100,000$ or higher & $160(55.4)$ \\
\hline Unknown & $48(16.6)$ \\
\hline \multicolumn{2}{|l|}{ Region } \\
\hline Northeast & $102(35.3)$ \\
\hline Midwest & $105(36.3)$ \\
\hline South & $31(10.7)$ \\
\hline West & $20(6.9)$ \\
\hline Unknown & $31(10.7)$ \\
\hline
\end{tabular}


Table 2 School Food Allergy Policies

\begin{tabular}{|c|c|c|c|}
\hline \multirow[t]{2}{*}{ Policy } & Yes & No & Unsure \\
\hline & \multicolumn{3}{|l|}{$N=289$} \\
\hline School is a generally safe environment & $210(72.7)$ & $54(18.7)$ & $25(8.7)$ \\
\hline \multicolumn{4}{|l|}{ Epinephrine Policies } \\
\hline Emergency (stock) epinephrine is available & $155(53.7)$ & $64(22.2)$ & \multirow[t]{2}{*}{$70(24.2)$} \\
\hline Policy is Helpful (if responded "Yes")/Needed (if responded "No") & $146(94.2)$ & $59(92.2)$ & \\
\hline Children are able to carry their medications & $167(57.8)$ & $86(29.8)$ & \multirow[t]{2}{*}{$36(12.5)$} \\
\hline Policy is Helpful/Needed & $156(93.4)$ & $47(54.7)$ & \\
\hline Child's epinephrine is readily available in the classroom & $145(50.2)$ & $129(44.6)$ & \multirow[t]{2}{*}{$15(5.2)$} \\
\hline Policy is Helpful/Needed & - & - & \\
\hline Emergency (stock) epinephrine available on all school field trips $(N=287)$ & $104(36.3)$ & $101(35.2)$ & \multirow[t]{8}{*}{$82(28.6)$} \\
\hline Policy is Helpful/Needed & $95(91.4)$ & $82(81.2)$ & \\
\hline \multicolumn{3}{|l|}{ Who carries epinephrine on field trips (if responded "Yes") } & \\
\hline Teacher & $60(58.3)$ & & \\
\hline School-appointed chaperone & $15(14.6)$ & & \\
\hline School nurse & $8(7.8)$ & & \\
\hline Unsure & $6(5.8)$ & & \\
\hline Other & $14(13.6)$ & & \\
\hline Emergency (stock) epinephrine available for after-school activities & $30(10.4)$ & $136(47.1)$ & $123(42.6)$ \\
\hline Policy is Helpful/Needed & $29(96.7)$ & $119(88.8)$ & \\
\hline \multicolumn{4}{|l|}{ Who carries epinephrine during after-school activities (if responded "Yes") } \\
\hline Athletic trainer & $1(3.3)$ & & \\
\hline School nurse & $3(10.0)$ & & \\
\hline School staff & $7(23.3)$ & & \\
\hline Other & $19(63.3)$ & & \\
\hline Emergency (stock) epinephrine travels with every group & $33(11.4)$ & $99(34.3)$ & $157(54.3)$ \\
\hline Policy is Helpful/Needed & $29(87.9)$ & $82(82.8)$ & \\
\hline \multicolumn{4}{|l|}{ Who carries epinephrine during after-school activities (if responded "Yes") } \\
\hline Athletic trainer & $1(3.0)$ & & \\
\hline School nurse & $4(12.1)$ & & \\
\hline School staff & $10(30.3)$ & & \\
\hline Coach/teacher & $9(27.3)$ & & \\
\hline Other & $11(33.3)$ & & \\
\hline \multicolumn{4}{|l|}{ Lunchroom Policies } \\
\hline Designated lunch areas for students with food allergies & $184(63.4)$ & $78(27)$ & $27(9.3)$ \\
\hline Policy is Helpful/Needed & $128(69.6)$ & $25(32.1)$ & \\
\hline School lunch menus with allergen information available & $100(34.6)$ & $128(44.3)$ & $61(21.1)$ \\
\hline Policy is Helpful/Needed & $93(93)$ & $110(85.9)$ & \\
\hline Food items are labeled with allergen information & $36(12.5)$ & $144(49.8)$ & $109(37.7)$ \\
\hline Policy is Helpful/Needed & $33(91.7)$ & $116(80.6)$ & \\
\hline Clear cleaning procedures in the lunchroom & $160(55.4)$ & $34(11.8)$ & $95(32.9)$ \\
\hline Policy is Helpful/Needed & $152(95)$ & $31(91.2)$ & \\
\hline \multicolumn{4}{|l|}{ Classroom Policies } \\
\hline Snack policy in the classroom & $178(61.6)$ & $98(33.9)$ & $13(4.5)$ \\
\hline Policy is Helpful/Needed & $159(89.3)$ & $63(64.3)$ & \\
\hline Strict food guidelines for celebrations (holidays and birthdays) $(\mathrm{N}=287)$ & $153(53.3)$ & $120(41.9)$ & $14(4.9)$ \\
\hline Policy is Helpful/Needed & $138(90.2)$ & $96(80)$ & \\
\hline
\end{tabular}


Table 2 School Food Allergy Policies (Continued)

\begin{tabular}{|c|c|c|c|}
\hline \multirow[t]{2}{*}{ Policy } & Yes & No & Unsure \\
\hline & \multicolumn{3}{|l|}{$N=289$} \\
\hline \multicolumn{4}{|l|}{ What are the recommendations (if responded "Yes") } \\
\hline Food with a clear ingredient label is allowed & 59 (38.6) & & \\
\hline No food is allowed & $48(31.4)$ & & \\
\hline Unsure & $4(2.6)$ & & \\
\hline Other & $42(27.5)$ & & \\
\hline \multicolumn{4}{|l|}{ Field Trip \& After-School Policies } \\
\hline When food is not provided by the school for field trips, all parents are provided with food guidelines & $74(25.6)$ & $154(53.3)$ & $61(21.1)$ \\
\hline Policy is Helpful/Needed & $58(78.4)$ & $104(69.3)$ & \\
\hline Strict food policies for after-school activities & $23(8.0)$ & $161(55.7)$ & $105(36.3)$ \\
\hline Policy is Helpful/Needed & $22(95.7)$ & $120(74.5)$ & \\
\hline Concessions are clearly labeled for food allergens & $18(6.2)$ & $152(52.6)$ & $119(41.2)$ \\
\hline Policy is Helpful/Needed & $18(100)$ & $133(87.5)$ & \\
\hline \multicolumn{4}{|l|}{ Food Allergy Education Policies } \\
\hline Training and education for students & $31(10.7)$ & $207(71.6)$ & $51(17.7)$ \\
\hline Policy is Helpful/Needed & $28(90.3)$ & $177(85.5)$ & \\
\hline Educational materials in the lunchroom relating to food allergy & $18(6.2)$ & $176(60.9)$ & $95(32.9)$ \\
\hline Policy is Helpful/Needed & $14(77.8)$ & $136(77.3)$ & \\
\hline Educational materials in the classroom relating to food allergy $(N=287)$ & $16(5.6)$ & $210(73.2)$ & \\
\hline Policy is Helpful/Needed & $13(81.3)$ & $161(76.7)$ & $61(21.3)$ \\
\hline \multicolumn{4}{|l|}{ Transportation Policies } \\
\hline Children take the school bus to/from school & $129(44.6)$ & $155(53.6)$ & $5(1.7)$ \\
\hline Adult on school bus to/from school is trained on allergic reactions (if responded "Yes") & $48(37.2)$ & $33(25.6)$ & $48(37.2)$ \\
\hline
\end{tabular}

approximately half of parents reported that their child was allowed to self-carry their epinephrine (57.8\%), that their child's epinephrine was readily available in the classroom (50.2\%), and that their child's school had non-student-specific stock epinephrine available (53. $7 \%)$. Stock epinephrine was less frequently reported to be available on field trips (36\%), after school $(10 \%)$ or to travel with groups to off-site after-school events (11. $4 \%)$. However, nearly one-quarter (24.2\%) of parents did not know if their child's school had stock epinephrine available, with $28.6 \%$ reporting uncertainty about epinephrine policies related to field trips and 54.3\% reporting uncertainty about epinephrine policies relating to after-school activities). The majority of parents who reported that policies related to epinephrine were in place felt that these policies were helpful (87.9-96.7\% depending on the policy). Similarly, nearly all parents who reported that epinephrine policies were not in place felt that such policies were needed (81.2-92.2\% depending on the policy). In the lunchroom, the policies most frequently reported to be in place were designated areas in the lunchroom for students with food allergy (63.4\%) and clear cleaning procedures (55.4\%). Parents were least likely to report that menus with allergen information were available to them (34.6\%) and that food items were labeled with allergen information $(12.5 \%)$. The majority of parents felt that the lunchroom policies in place in their child's school were helpful (95-91.7\%) or that such policies were needed (91.2$80.6 \%)$, with the exception of having designated lunch areas for students with food allergy (helpful $=69.6 \%$, needed $=32.1 \%$ ).

In the classroom, a snack policy was reported to be in place by $61.6 \%$ of parents and strict food guidelines for celebrations were reported by $53.3 \%$. These policies were deemed helpful by 89.3 and $90.2 \%$ of parents, respectively. While $80 \%$ of parents who reported that classroom celebration food guidelines were not in place felt they were needed, only $64.3 \%$ felt a classroom snack policy was needed.

Policies related to food allergy education and training were among the least-frequently reported. While $37.2 \%$ reported that an adult on their child's bus was trained in the use of epinephrine, only $10.7 \%$ reported that food allergy education/training were available for students, $6.2 \%$ reported that lunchroom educational materials were available, and $5.6 \%$ reported that classroom educational materials were available. However, the majority of parents felt that such policies were helpful (90.3-77.8\%) or needed (85.5-76.7\%). 
Policies related to field trips and after-school were also among those less frequently reported to be in place. One-quarter $(25.6 \%)$ of parents reported that food guidelines were provided for field trips, $8.0 \%$ reported that strict food policies were in place for after-school activities, and $6.2 \%$ reported that concessions were labeled with allergen information. However, many parents reported being unsure of whether their child's school had these policies (concessions labeled $=37.7 \%$, after school food policies $=36.3 \%$ ). The majority of parents felt that field trip and after-school policies were either helpful (100-78.4\%) or needed (87.5-69.3\%).

\section{Associations between food allergy policies and school characteristics}

Significant associations were noted between several food allergy policies and student age (Table 3). As expected, more students were reported to be allowed to self-carry epinephrine in high school and middle school as compared to elementary school $(91.4,78.3,47.3 \%, p<0.01)$. Parents of elementary and middle school students reported that their child's school had designated areas in the lunchroom (elementary $=72.5 \%$, middle $=67.4 \%$, high $=20.0 \%, p<0.01$, clear lunchroom cleaning procedures (elementary $=60.4 \%$, middle $=65.3 \%$, high $=20.0 \%$, $p<0.01$ ), and strict classroom policies for snacks (elementary $=69.8 \%, \quad$ middle $=52.2 \%$, high $=31.4 \%, \quad p<0.01)$ and celebrations (elementary $=56.6 \%$, middle $=54.4 \%$, high $=34.3 \%, p<0.01$ ) more frequently than parents of high school students.

School type (public versus private) was also significantly associated with reported food allergy policies (Table 4). Parents of children attending public schools more frequently reported that their child's school had a designated area in the lunchroom compared to private schools $(67.4 \%$ vs $50 \%, p<0.05)$. Parents of children attending private schools more frequently reported that their child's epinephrine was available in the classroom $(62.9 \%$ vs $46.7 \%, p<0.05)$ and that strict food guidelines were in place for field trips when food was not provided by the school $(38.7 \%$ vs $22 \%, p<0.01)$. Finally, parents of children in private schools more frequently reported that students were provided with training and education on food allergy $(17.7 \%$ vs $8.8 \%, p<0.05)$ and that educational materials on food allergy were available in the lunchroom $(14.5 \%$ vs $4 \%, p<0.01)$.

Differences in food allergy policy were also identified based on geographic location (Table 5). Parents in the Northeast more frequently reported that food items in the lunchroom were labeled with allergen information as compared to other regions $(\mathrm{NE}=19.6 \%, \mathrm{MW}=9.5 \%$, South $=3.2 \%$, West $=0 \%, p<0.05)$. Parents in the Northeast and Midwest more frequently reported strict food allergy guidelines for classroom celebrations as compared to those in the South and West $(\mathrm{NE}=59.8 \%, \mathrm{MW}=56$. $2 \%$, South $=35.5 \%$, West $=30.0 \%, p<0.05)$. Parents of students who rode the school bus to/from school in the South more frequently reported that there is an adult present on the school bus who was trained in the management of allergic reactions as compared to parents in the Northeast, Midwest, and West (South $=81.3 \%, \mathrm{NE}=24$. $6 \%, \mathrm{MW}=43.3 \%$, West $=25 \% ; p<0.01)$.

\section{Discussion}

The health and safety needs of students must be met so that children can thrive and achieve their academic potential in a safe and inclusive environment. To date, given the lack of research on the most effective strategies to manage food allergy in the school setting and the subsequent lack of standardized national and local requirements, schools use a variety of approaches to manage food allergy and to minimize the risk of accidental exposures to food allergens. To our knowledge, the present study was one of the first to report on school food allergy polices from the perspective of parents of children with food allergy. Importantly, approximately one in five parents in our study did not feel that their food allergic child was safe while at school. Significant variations were reported in food allergy management and anaphylaxis preparedness strategies and appeared to be affected by the age of the student body, type of school (public versus private), and geographic location. Additionally, while the majority of parents felt that the polices in place in their child's school were helpful, most also believed that the implementation of additional polices was necessary, including policies related to epinephrine access, labeling of food items, and food allergy education and training.

Half of the parents in our study reported that their child's school carried non-student-specific stock epinephrine, with an additional one-quarter being unaware of whether their child's school had stock epinephrine available. Over $90 \%$ of parents felt that this policy was either helpful or needed. Whereas most states have legislation allowing schools to voluntarily stock undesignated epinephrine auto-injectors (EAI), few states have legislative mandates requiring that schools do so $[11,12]$. In states without a mandate, barriers to stock epinephrine availability may include administrative and staff resistance, lack of adequate staff education, and cost [13-15]. However, given that prompt administration of epinephrine is the only life-saving treatment for anaphylaxis and that $25 \%$ of cases of anaphylaxis in schools occur in children previously undiagnosed with a food allergy $[9,16,17]$, improving the availability of stock epinephrine should be a priority in improving the management of food allergy in the school setting. The majority of parents also desired that stock epinephrine be available on school field trips and during after-school activities. Such policies may pose 
Table 3 Unadjusted Association with Outcomes: Grade Level (Yes vs. No/Unsure/No Response)

\begin{tabular}{|c|c|c|c|c|}
\hline \multirow[t]{3}{*}{ Policy } & \multicolumn{4}{|l|}{ Grade Level } \\
\hline & Elementary & Middle & High & Unknown \\
\hline & $N=182$ & $N=46$ & $N=35$ & $N=26$ \\
\hline School is a generally safe environment & $137(75.3)$ & $34(73.9)$ & $24(68.6)$ & $15(57.7)$ \\
\hline \multicolumn{5}{|l|}{ Epinephrine Policies } \\
\hline Emergency (stock) epinephrine is available & $95(52.2)$ & $28(60.9)$ & $20(57.1)$ & $12(46.2)$ \\
\hline Children are able to carry their medications & $86(47.3)$ & $36(78.3)$ & $32(91.4)$ & $13(50.0)^{* *}$ \\
\hline Child's epinephrine is readily available in the classroom & $94(51.7)$ & $22(47.8)$ & $16(45.7)$ & $13(50.0)$ \\
\hline Emergency (stock) epinephrine available on all school field trips & $63(34.6)$ & $20(13.4)$ & $9(25.7)$ & $12(46.2)$ \\
\hline Emergency (stock) epinephrine available for after-school activities & $14(7.7)$ & $10(21.7)$ & $4(11.4)$ & $2(7.7)$ \\
\hline Emergency (stock) epinephrine travels with groups outside of school & $18(9.9)$ & $6(13.0)$ & $5(14.3)$ & $4(15.4)$ \\
\hline \multicolumn{5}{|l|}{ Lunchroom Policies } \\
\hline Designated lunch areas for students with food allergies & $132(72.5)$ & $31(67.4)$ & $7(20.0)$ & $14(53.9)^{* *}$ \\
\hline School lunch menus with allergen information available & $54(29.7)$ & $18(39.1)$ & $16(45.7)$ & $12(46.2)$ \\
\hline Food items are labeled with allergen information & $24(13.2)$ & $4(8.7)$ & $5(14.3)$ & $3((11.5)$ \\
\hline Clear cleaning procedures in the lunchroom & $110(60.4)$ & $30(65.2)$ & $7(20.0)$ & $13(50.0)^{* *}$ \\
\hline \multicolumn{5}{|l|}{ Classroom-Specific Policies } \\
\hline Snack policy in the classroom & $127(69.8)$ & $24(52.2)$ & $11(31.4)$ & $16(61.5)^{* *}$ \\
\hline Strict food guidelines for celebrations (holidays and birthdays) & $103(56.6)$ & $25(54.4)$ & $12(34.3)$ & $13(50)^{* *}$ \\
\hline \multicolumn{5}{|l|}{ Field Trip \& After School Policies } \\
\hline $\begin{array}{l}\text { When food is not provided by the school for field trips, } \\
\text { all parents are provided with food guidelines }\end{array}$ & $52(28.6)$ & $10(21.7)$ & $5(14.3)$ & $7(26.9)$ \\
\hline Strict food policies for after-school activities & $14(7.7)$ & $5(6.5)$ & $0(0.0)$ & $3(11.5)$ \\
\hline Concessions are clearly labeled for food allergens & $11(6.0)$ & $4(8.7)$ & $0(0.0)$ & $3(11.5)$ \\
\hline \multicolumn{5}{|l|}{ Food Allergy Education Policies } \\
\hline Training and education for students & $22(12.1)$ & $5(10.9)$ & $2(5.7)$ & $2(7.7)$ \\
\hline Educational materials in the lunchroom relating to food allergy & $8(4.4)$ & $5(10.9)$ & $2(5.7)$ & $3(11.5)$ \\
\hline Educational materials in the classroom relating to food allergy & $9(5.0)$ & $2(4.4)$ & $2(5.7)$ & $3(11.5)$ \\
\hline Children take school bus to/from school & $82(45.1)$ & $25(54.4)$ & $14(40.0)$ & $8(30.8)$ \\
\hline Adult on school bus is trained on allergic reactions & $32(39.0)$ & $12(48.0)$ & $2(14.3)$ & $2(25.0)$ \\
\hline
\end{tabular}

${ }^{* *} p<0.01,{ }^{*} p<0.05$

a challenge for schools, as they require the availability of additional EAIs. However, as up to $19 \%$ of anaphylactic reactions during the school day occur outside the school building or on field trips, the availability of stock EAIs for these situations is an important measure to consider [18].

Several policies were infrequently reported to be in place, but frequently deemed to be needed. Half of parents reported that food items sold at lunch and concessions after-school were not labeled with allergen information, though over $80 \%$ felt that such labeling should be implemented. Similarly, only $44 \%$ of parents indicated that lunch menus with allergen information were available to them, with $85 \%$ feeling that this policy was needed. Because thorough review of ingredients in all food and drink products prior to consumption is a core strategy for food allergen avoidance and anaphylaxis prevention [19] widespread implementation of ingredient labeling policies should be prioritized in order to protect students and prevent potential allergic reactions at school. Similarly, policies related to food allergy training and education (i.e., student education, materials available in the lunchroom and classroom, and training of school bus staff) were among those least frequently reported to be in place, though approximately four in five parents felt that such policies should to be implemented. Educational programs have been shown to be effective in increasing food allergy knowledge as well as appropriate use of an EAI and may be an additional key area of policy on which to focus [20,21].

Expectedly, several school food allergy polices appeared to be driven by the age of the student body. For instance, parents of elementary and middle school students more frequently reported designated lunch areas and food allergy policies for classroom snacks and 
Table 4 Unadjusted Association with Outcomes: Public vs. Private (Yes vs. No/Unsure/No Response)

\begin{tabular}{|c|c|c|}
\hline \multirow[t]{3}{*}{ Policy } & \multicolumn{2}{|c|}{ Type of School } \\
\hline & Private & Public \\
\hline & $N=62$ & $N=227$ \\
\hline School is a generally safe environment & $44(71.0)$ & $166(73.1)$ \\
\hline \multicolumn{3}{|l|}{ Epinephrine Policies } \\
\hline Emergency (stock) epinephrine is available & $29(46.8)$ & $126(55.1)$ \\
\hline Children are able to carry their medications & $37(59.7)$ & $130(57.3)$ \\
\hline Child's epinephrine is readily available in the classroom & $39(62.9)$ & $106(46.7)^{*}$ \\
\hline Emergency (stock) epinephrine available on all school field trips & $25(40.3)$ & $79(34.8)$ \\
\hline Emergency (stock) epinephrine available for after-school activities & $9(14.5)$ & $21(9.3)$ \\
\hline Emergency (stock) epinephrine travels with groups outside of school & $9(14.5)$ & $24(10.6)$ \\
\hline \multicolumn{3}{|l|}{ Lunchroom Policies } \\
\hline Designated lunch areas for students with food allergies & $31(50.0)$ & $153(67.4)^{*}$ \\
\hline School lunch menus with allergen information available & $18(29.0)$ & $82(36.1)$ \\
\hline Food items are labeled with allergen information & $9(14.5)$ & $27(11.9)$ \\
\hline Clear cleaning procedures in the lunchroom & $37(59.7)$ & $123(54.2)$ \\
\hline \multicolumn{3}{|l|}{ Classroom Policies } \\
\hline Snack policy in the classroom & $36(58.1)$ & $142(62.6)$ \\
\hline Strict food guidelines for celebrations (holidays and birthdays) & $27(43.6)$ & $126(55.5)$ \\
\hline \multicolumn{3}{|l|}{ Field Trip \& After-School Policies } \\
\hline When food is not provided by the school for field trips, all parents are provided with food guidelines & $24(38.7)$ & $50(22.0)^{* *}$ \\
\hline Strict food policies for after-school activities & $8(12.9)$ & $15(6.6)$ \\
\hline Concessions are clearly labeled for food allergens & $4(6.5)$ & $14(6.2))$ \\
\hline \multicolumn{3}{|l|}{ Food Allergy Education Policies } \\
\hline Training and education for students & $11(17.7)$ & $20(8.8)^{*}$ \\
\hline Educational materials in the lunchroom relating to food allergy & $9(14.5)$ & $9(4.0)^{* *}$ \\
\hline Educational materials in the classroom relating to food allergy & $5(8.1)$ & $11(4.9)$ \\
\hline Children take school bus to/from school & $17(27.4)$ & $112(49.3)$ \\
\hline Adult on school bus is trained on allergic reactions & $6(35.3)$ & $42(37.5)$ \\
\hline
\end{tabular}

${ }^{* *} p<0.01,{ }^{*} p<0.05$

celebrations compared to parents of high school students. These differences are likely age-appropriate, as younger children are less developmentally and cognitively ready to self-manage and to minimize their risk of accidental food allergen ingestions. Similarly, middle and high school students were more frequently reported to be allowed to self-carry epinephrine, which is consistent with greater autonomy and food allergy selfmanagement skills with age. Importantly, adolescents remain at greatest risk of poor outcomes from food allergy [22-24]. This unique population may therefore particularly benefit from increased training and education on food allergy, a policy which was desired by the majority of survey respondents.

Differences in school policy also appeared to exist between public and private schools. Private schools provided their students with more food allergy training and education, had stricter food guidelines for field trips when food was not provided by the school, and were more likely to have epinephrine available in the classroom. These differences may be based on variations in financial and time resources, staffing, and level of school nurse coverage. Parents of children with food allergy may also have more influence in shaping policy decisions at private as compared to public schools.

Although the majority of parents felt that their child's school was generally safe, one in four were not sure or did not consider the school environment to be safe for their food allergic child. Such anxiety about safety and the potential for allergic reactions may negatively impact quality of life for students and their families and adversely affect school attendance $[25,26]$. Further study is warranted to investigate the reasons behind these negative perceptions and potential opportunities for 
Table 5 Unadjusted Association with Outcomes: Region (Yes vs. No/Unsure/No Response)

\begin{tabular}{|c|c|c|c|c|c|}
\hline \multirow[t]{3}{*}{ Policy } & \multicolumn{5}{|l|}{ Region } \\
\hline & Northeast & Midwest & South & West & Unknown \\
\hline & $N=102$ & $N=105$ & $N=31$ & $N=20$ & $N=31$ \\
\hline School is generally safe environment & $82(80.4)$ & $75(71.4)$ & $22(71.0)$ & $11(55.0)$ & $20(64.5)$ \\
\hline \multicolumn{6}{|l|}{ Epinephrine Policies } \\
\hline Emergency (stock) epinephrine is available & $54(52.9)$ & $59(56.2)$ & $17(54.8)$ & $8(40.0)$ & $17(54.8)$ \\
\hline Children are able to carry their medications & $52(51.0)$ & $65(61.9)$ & $17(54.8)$ & $13(65.0)$ & $20(64.5)$ \\
\hline Child's epinephrine is readily available in the classroom & $46(45.1)$ & $57(54.3)$ & $18(58.1)$ & $7(35.0)$ & $17(54.8)$ \\
\hline Emergency (stock) epinephrine available on all school field trips & $34(33.3)$ & $42(40.0)$ & $12(38.7)$ & $2(10.0)$ & $14(45.2)$ \\
\hline Emergency (stock) epinephrine available for after-school activities & $9(8.82)$ & $16(15.2)$ & $3(9.7)$ & $1(5.0)$ & $1(3.2)$ \\
\hline Emergency (stock) epinephrine travels with groups outside of school & $13(12.8)$ & $11(10.5)$ & $1(3.2)$ & $1(5.0)$ & $7(22.6)$ \\
\hline \multicolumn{6}{|l|}{ Lunchroom Policies } \\
\hline Designated lunch areas for students with food allergies & $63(61.8)$ & $74(70.5)$ & $20(64.5)$ & $8(40.0)$ & $19(61.3)$ \\
\hline School lunch menus with allergen information available & $36(35.3)$ & $28(26.7)$ & $14(45.2)$ & $9(45.0)$ & $13(41.9)$ \\
\hline Food items are labeled with allergen information & $20(19.6)$ & $10(9.5)$ & $1(3.2)$ & $0(0.0)$ & $5(16.1)^{*}$ \\
\hline Clear cleaning procedures in the lunchroom & $60(58.8)$ & $57(54.3)$ & $18(58.1)$ & $9(45.0)$ & $16(51.6)$ \\
\hline \multicolumn{6}{|l|}{ Classroom Policies } \\
\hline Snack policy in the classroom & $64(62.8)$ & $70(66.7)$ & $20(64.5)$ & $8(40.0)$ & $16(51.6)$ \\
\hline Strict food guidelines for celebrations (holidays and birthdays) & $61(59.8)$ & $59(56.2)$ & $11(35.5)$ & $6(30.0)$ & $16(51.6)^{*}$ \\
\hline \multicolumn{6}{|l|}{ Field Trip \& After-School Policies } \\
\hline $\begin{array}{l}\text { When food is not provided by the school for field trips, } \\
\text { all parents are provided with food guidelines }\end{array}$ & $30(29.4)$ & $24(22.9)$ & $6(16.1)$ & $4(20.0)$ & $11(35.5)$ \\
\hline Strict food policies for after-school activities & $8(7.8)$ & $11(10.5)$ & $0(0.0)$ & $1(5.0)$ & $3(9.7)$ \\
\hline Concessions are clearly labeled for food allergens & $6(5.9)$ & $6(5.7)$ & $0(0.0)$ & $2(10.0)$ & $4(12.9)$ \\
\hline \multicolumn{6}{|l|}{ Food Allergy Education Policies } \\
\hline Training and education for students & $10(9.8)$ & $13(12.4)$ & $3(9.7)$ & $2(10.0)$ & $3(9.7)$ \\
\hline Educational materials in the lunchroom relating to food allergy & $5(4.9)$ & $9(8.6)$ & $2(6.5)$ & $1(5.0)$ & $1(3.2)$ \\
\hline Educational materials in the classroom relating to food allergy & $5(4.9)$ & $4(3.8)$ & $3(9.7)$ & $2(10.0)$ & $2(6.45)$ \\
\hline Children take school bus to/from school & $65(63.7)$ & $30(28.6)$ & $16(51.6)$ & $4(20.0)$ & $14(45.2)$ \\
\hline Adult on school bus is trained on allergic reactions & $16(24.6)$ & $13(43.3)$ & $13(81.3)$ & $1(25.0)$ & $5(35.7)^{* *}$ \\
\hline
\end{tabular}

${ }^{* *} p<0.01,{ }^{*} p<0.05$

improvement. For example, clear documentation of student-specific medical needs with medical forms (e.g. individualized health plan, anaphylaxis emergency plan, school 504 plan), clear labeling of food items sold at school, an adequate supply of appropriate medications (including stock epinephrine), and food allergy/anaphylaxis education for school staff may improve parental perceptions of safety during the school day [4, 27-29].

It is also notable that parents were frequently unaware of whether certain food allergy policies were in place in their child's school. For instance, 40-50\% were unsure about the availability of stock epinephrine for afterschool activities and approximately $40 \%$ were uncertain of whether food items sold at lunch or after school were labeled with allergen information. It is possible that many parents were not affected by such policies (e.g., children brought their own food to school or did not participate in after-school activities). However, clear and timely communication and a collaborative approach between the student's school and family may provide an opportunity to help parents be more aware about policies that are in place and therefore feel that school is a safer environment for their food allergic child [30].

Several limitations of our study should be mentioned. The use of self-report in data collection includes inherent risk to internal validity related to inaccurate recall bias, selective recall bias and social desirability bias. Additionally, respondents were recruited through food allergy support and advocacy organizations and were predominantly Caucasian, college-educated, and highincome individuals. Additionally, the survey was distributed exclusively online, in English. Such limitations suggest that these findings may not be generalizable to the broader U.S. population of families with food 
allergies. For example, parents with higher household income may be more likely to have children at schools in good financial standing and with more resources available for food allergy management. Future efforts should be made to include underrepresented groups from a more diverse socioeconomic background, in hopes of having a more representative population. Lastly, given the nature of the survey, our results are undoubtedly affected by the potential lack of parental awareness regarding specific food allergy policies. This lack of awareness, however, is also a notable finding.

\section{Conclusion}

This study demonstrates that while most schools reportedly have one or more food allergy policies in place, a substantial proportion of parents have concerns over the safety of their child in the school setting. Many parents feel that additional policies are necessary to improve the safety of the school environment for children with food allergy. The availability of stock epinephrine, improved allergen labeling of food and menus provided by the school and increased food allergy education may be key areas of policy on which to focus. Additionally, many parents may not be aware of all the policies that are already in place in their child's school, which highlights the importance of maintaining an ongoing dialogue between parents, school administration, school nurses, pediatric health care providers, and school staff. There also appears to be differences in food allergy policies related to student age, school type, and geographic location. Future studies may investigate the reasons behind such policy variations and identify those policies that are most effective in creating a safe school environment, thus promoting better clinical outcomes for children with food allergy in the school setting.

\section{Abbreviation}

EAl: Epinephrine auto-injector

\section{Acknowledgements}

The authors would like to thank the Allergy \& Asthma Network and Marilyn Freund for supporting this research. We would also like to thank Tonya Winders (Allergy \& Asthma Network) and Marjorie Rae Yarbrough for providing insight and expertise that greatly assisted the research.

\section{Funding}

All phases of this study were supported by Marilyn Freund and the Allergy and Asthma Network, Vienna, Virginia.

\section{Availability of data and materials}

The datasets used and analyzed during the current study are available from the corresponding author on reasonable request.

\section{Authors' contributions}

SSM drafted the initial manuscript and reviewed and revised the manuscript. $A R, O K, L K$, and JW reviewed and revised the manuscript. DH assembled, cleaned and performed an initial analysis of the data. BS conducted the data analysis. RG conceptualized and designed the study and reviewed and revised the manuscript; and all authors approved the final manuscript as submitted.

\section{Ethics approval and consent to participate}

Informed consent was obtained before a participant could access the survey. This study was deemed exempt by the Institutional Review Board of Northwestern University.

\section{Competing interests}

The authors declare that they have no competing interests.

\section{Publisher's Note}

Springer Nature remains neutral with regard to jurisdictional claims in published maps and institutional affiliations.

\section{Author details \\ 'Rochester Regional Health, Rochester, NY, USA. ${ }^{2}$ University of Rochester School of Medicine and Dentistry, Rochester, NY, USA. ${ }^{3}$ Food Allergy \& Anaphylaxis Michigan Association, Ann Arbor, MI, USA. ${ }^{4}$ Molloy College, Rockville Centre, New York, USA. ${ }^{5}$ Northwestern University Feinberg School of Medicine, Chicago, IL, USA. ${ }^{6}$ Center of Innovation for Complex Chronic Healthcare, Edward J. Hines, Jr. Veterans Affairs Hospital, Hines, IL, USA. ${ }^{7}$ Icahn School of Medicine at Mount Sinai, New York, NY, USA. ${ }^{8}$ Ann \& Robert H. Lurie Children's Hospital of Chicago, Chicago, IL, USA. ${ }^{9}$ Center for Community Health, Northwestern University Feinberg School of Medicine, 750 N Lake Shore Dr., 6th Floor, Chicago, IL 60611, USA.}

Received: 3 November 2017 Accepted: 30 April 2018

Published online: 12 May 2018

\section{References}

1. Gupta RS, Springston EE, Warrier MR, Smith B, Kumar R, Pongracic J, Holl JL. Pediatrics. 2011;128(1):e9-17.

2. Liu AH, Jaramillo R, Sicherer SH, Wood RA, Bock SA, Burks AW, Massing M, Cohn RD, Zeldin DC. J Allergy Clin Immunol. 2010;126(4):798-806.

3. Sampath V, Sindher SB, Zhang W, Nadeau KC. Annals Allergy Asthma Immunol. 2018;120:254-62.

4. United States Centers for Disease Control and Prevention. Voluntary guidelines for managing food allergies in schools and early care and education programs. https:/www.cdc.gov/healthyschools/foodallergies/pdf/ 13_243135_A_Food_Allergy_Web_508.pdf. Accessed 25 Mar 2018.

5. Hogue SL, Goss D, Hollis K, Silvia S, White MV. J Asthma Allergy. 2016;9:109-15.

6. Nowak-Wegrzyn A, Conover-Walker MK, Wood RA. Arch Ped Adolest Med. 2001;155(7):790-5

7. White MV, Hogue SL, Bennett ME, Gross D, Millar K, Hollis K, Siegel PH, Wolf RA, Wooddell MJ, Silvia S. Allergy Asthma Proc. 2015;36(4):306-12.

8. OToole TP, Anderson S, Miller C, Guthrie J. J Sch Health. 2007:77(8):500-21.

9. Sicherer SH, Furlong TJ, DeSimone J, Sampson HA. J Pediatrics. 2001;138(4): 560-5.

10. Harris PA, Taylor R, Thielke R, Payne J, Gonzalez N, Conde JG. J Biomed Inform. 2009:42(2):377-81.

11. Allergy and Asthma Network (AAN). School stock epinephrine laws. http:// www.allergyasthmanetwork.org/advocacy/current-issues/stock-epinephrine. Accessed 25 March 2017

12. Food Allergy Research and Education (FARE). School access to epinephrine map. Available from: https://www.foodallergy.org/advocacy/epinephrine/ map. Accessed 25 Mar 2017

13. Morris P, Baker D, Belot C, Edwards A. J School Health. 2011:81 (8):471-6.

14. Hogue SL, Goss D, Kelly Hollis SS, White MV. J Asthma Allergy. 2016;9:109-15.

15. Shah SS, Parker CL, Smith EB, Davis CM. J Allergy Clin Immunol IP. 2014;2(3): 288-93.

16. Mclntyre CL, Sheetz AH, Carroll CR, Young MC. Pediatrics. 2005:116(5):1134-40.

17. Sicherer SH, Mahr T. American Academy of Pediatrics section on allergy and immunology. Pediatrics. 2010;126(6):1232-9.

18. McIntyre CL, Sheetz AH, Carroll CR, Young MC. Pediatrics. 2005;11695:1134-40.

19. Boyce JA, Assa'ad A, Burks AW, et al. J Allergy Clin Immunol. 2010;126(6 suppl):S1-S58.

20. Shah SS. Parker CL. Davis CM Clin Pediatr. 2013;52(9):812-20.

21. Wahl A, Stephens H, Ruffo M, Jones AL. J School Nursing. 2015;31(2):91-8.

22. Bock SA, Munoz-Furlong A, Sampson HA. J Allergy Clin Immunol. 2001; 107(1):191-3.

23. Sampson MA, Munoz-Furlong A, Sicherer SH. J Allergy Clin Immunol. 2006; 117(6):1440-5

24. Munoz-Furlong A, Weiss CC. Current All Asthma Reports. 2009;9(1):57-63. 
25. Bollinger ME, Dahlquist LM, Mudd K, Sonntag C, Dillinger L, McKenna K. Ann Allergy Asthma Immunol. 2006;96(3):415-21.

26. Springston EE, Smith B, Shulruff J, Pongracic J, Holl JL, Gupta RS. Ann Allergy Asthma Immunol. 2010;105(4):287-94.

27. Pistiner M, Devore CD. Pediatr Ann. 2013;42(8):334-40.

28. Russell AF, Huber MM. J Asthma Allergy Educ. 2013;4(6):290-304.

29. Wang J, Sicherer SH. Pediatrics. 2017;139(3):e20164005.

30. Rivkina V, Tapke DE, Cardenas LD, Harvey-Gintoft B, Whyte SA, Gupta RS. BMC Public Health. 2014;14(1):1250

Ready to submit your research? Choose BMC and benefit from:

- fast, convenient online submission

- thorough peer review by experienced researchers in your field

- rapid publication on acceptance

- support for research data, including large and complex data types

- gold Open Access which fosters wider collaboration and increased citations

- maximum visibility for your research: over $100 \mathrm{M}$ website views per year 